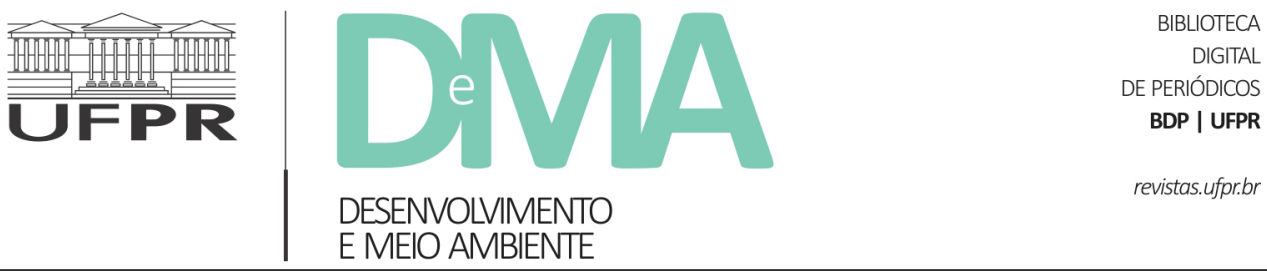

\title{
Mineração da pedra "São Thomé" em São Thomé das Letras - MG: um estudo etnográfico sobre saúde coletiva e justiça ambiental
}

\section{The mining of "São Thomé" rock in São Thomé das Letras-MG: an ethnographic study about collective health and environmental justice}

\author{
Bruna Marcelo Bernardo MOREIRA ${ }^{1}$, Luiz Felipe SILVA ${ }^{1 *}$, Maria Isabel Cardoso da Silva BUENO² \\ ${ }^{1}$ Universidade Federal de Itajubá (UNIFEI), Itajubá, MG, Brasil. \\ ${ }^{2}$ Universidade Federal de Viçosa (UFV), Viçosa, MG, Brasil. \\ *E-mail para contato: 1felipe@unifei.edu.br
}

Artigo recebido em 18 de fevereiro de 2019, versão final aceita em 15 de maio de 2020, publicado em 16 de setembro de 2020.

\begin{abstract}
RESUMO: A atividade de mineração, incluindo a de não-metálicos, tem uma participação expressiva no modelo de desenvolvimento vigente. As cavas de exploração da pedra São Thomé abraçam e se confundem com o município de São Thomé das Letras, sul de Minas Gerais. Este estudo, por meio de etnografia, teve o objetivo de investigar a percepção dos moradores do município em relação aos impactos da mineração nos âmbitos da saúde coletiva e da justiça ambiental, considerando a ocorrência de silicose nos trabalhadores do setor e a proximidade das frentes de lavra e do centro urbano da cidade. $O$ trabalho de campo, realizado entre março e julho de 2017, se inseriu no cotidiano da comunidade e incluiu a observação como meio de conhecer melhor a realidade vivida em São Thomé das Letras. Nesse período foram realizadas entrevistas semiestruturadas, gravadas e não-gravadas, tanto com pessoas que trabalham ou já trabalharam na mineração como outros membros da comunidade. Para a análise dos dados foi utilizada a metodologia de análise de relatos orais, que possibilitou o tratamento das informações para atender ao objetivo da pesquisa. Moradores e trabalhadores percebem que a mineração influencia na saúde da comunidade e pelos relatos colhidos, observa-se que a questão da justiça ambiental é expressa nas falas. A análise também revela que a comunidade é refém da atividade de mineração, no modelo predominante, fonte de dor na paisagem humana e ambiental e de sobrevivência.
\end{abstract}

Palavras-chave: mineração; saúde coletiva; justiça ambiental; antropologia cultural. 
ABSTRACT: Mining activity, including that of non-metals, has a significant participation in the current development model. The stone digging caves "São Thomé" embraces and get mixed with the municipality of São Thomé das Letras, south of Minas Gerais. This study, through ethnography, aimed to investigate the perception of the inhabitants of the municipality regarding the impacts of mining in the areas of collective health and environmental justice, considering the occurrence of silicosis in workers of the sector and the proximity of the fronts of culture and the urban center of the city. The fieldwork, carried out between March and July 2017, was part of the daily life of the community and included observation as a way to better understand the reality of São Thomé das Letras. During this period, semi-structured, recorded and unrecorded interviews were carried out, both with people who work or already worked in mining and other members of the community. For the analysis of the data, the methodology of analysis of oral reports was used, which enabled the treatment of the information to satisfy the objective of the research. Residents and workers perceive that mining influences the health of the community and the reports collected, it is observed that the issue of environmental justice is expressed and felt in the speeches. The perception also reveals that the community is hostage to the mining activity, in the predominant model, source of survival, as well as pain in the human and environmental landscape.

Keywords: mining; collective health; environmental justice; cultural anthropology.

\section{Introdução}

A mineração é uma importante atividade econômica para a manutenção do modo de produção e do modelo de desenvolvimento atual, e uma das indústrias mais importantes para a economia do Brasil, país com grande variedade geológica e ampla gama de commodities minerais, com potencial de exploração integral nos marcos de um modelo econômico neoextrativista, primário-exportador. Entre os produtos desta indústria, há minerais não-metálicos, como rochas ornamentais, usadas principalmente pelo setor de construção civil, como mármore, granito e quartzito. Tamanha a importância deste tipo de produto que, de acordo com dados do Departamento Nacional de Produção Mineral (DNPM, 2014; DNPM, 2015), nos anos 2013 e 2014 , o país foi o $4^{\circ}$ maior produtor de rochas ornamentais do mundo.

A denominada pedra "São Thomé", como é conhecida no Brasil, ou tecnicamente como quartzito plaqueado ou foliado, é extraída destacadamente nos estados de Goiás e Minas Gerais. Neste último a produção se dá com destaque nas regiões de Alpinópolis, Ouro Preto, Diamantina e na cidade de São Thomé das Letras, na região sul do estado. Seus principais usos estão relacionados à construção civil, como piso e revestimento. A composição mineral do produto encontrado em São Thomé é de $95-98 \%$ de quartzo e $3-5 \%$ de muscovita, demais minerais são encontrados em percentuais ínfimos (FEAM, 2009).

O quartzo, principal composto mineral da pedra São Tomé, é a forma cristalina da sílica, ou dióxido de silício $\left(\mathrm{SiO}_{2}\right)$, sendo um dos óxidos mais bastos da superfície terrestre e sua inalação, pelos trabalhadores e pela população residente nas áreas de entorno da atividade mineral, está associada a doenças como tuberculose pulmonar, doença pulmonar obstrutiva crônica e efisema pulmonar. A Agência Internacional de Pesquisa em Câncer (IARC) incluiu a sílica como agente carcinogênico em 1997 (Barbosa et. al., 2011). 
Além desses desfechos desfavoráveis à saúde, a exposição à poeira contendo sílica livre é responsável pela doença ocupacional, clássica, a silicose. Trata-se de uma pneumoconiose ocasionada pela inalação da sílica em sua forma cristalina. Segundo o Ministério da Saúde essa doença pode se desenvolver de três formas: a crônica, pela exposição à sílica livre cristalina após longos períodos, superiores a dez anos; a subaguda, decorrente da exposição ocupacional a poeiras respiráveis com elevada concentração de sílica cristalina, manifestando-se entre cinco e dez anos do início da exposição; e a silicose em sua forma aguda, ocasionada pela exposição a grandes quantidades de poeira de sílica recém-fraturadas, com manifestação após poucos meses ou poucos anos de exposição (Ribeiro, 2010).

A mineração é atividade altamente impactante, é ainda mais no Brasil, para a saúde de seus trabalhadores, em especial a dos minerais não-metálicos, setor no qual 55,6\% dos trabalhadores, no ano de 2007, estavam expostos à sílica (Ribeiro, 2010). Não foram encontrados dados mais recentes em nível nacional. A pedra São Thomé é rocha com alta concentração de sílica, que possui até $98 \%$ do composto em sua composição (FEAM, 2009).

Em atividades como a mineração, na qual a fratura das rochas pode gerar material particulado, de fácil dispersão no ar, a preocupação com a ocorrência de silicose é uma realidade. Conforme dados do Ministério da Saúde, estima-se que no Brasil o número de trabalhadores formais expostos à poeira contendo sílica chega a seis milhões. Minas Gerais foi o estado com maior número de casos registrados pelo Sistema Nacional de Agravos e Notificações (SINAN) entre 2006 e 2009, totalizando 94 casos no período (Ribeiro, 2010).
Impactos expressivos ao meio ambiente e às comunidades do entorno, tanto pela própria exploração da área original quanto pela geração de resíduos invariavelmente têm sido predominantes no processo de mineração. As consequências danosas decorrentes da extração mineral ocorrem tanto na lavra como no beneficiamento, estocagem e transporte e repercutem na população em forma de poeira, ruído, vibração, entre outros. No tocante à atividade em São Thomé das Letras, o processo de mineração historicamente tem produzido impactos relevantes no quadro socioambiental da região, causando desmatamento, assoreando cursos d'água, prejuízos em nascentes, em mananciais, na qualidade de vida dos habitantes da cidade, além de interferir negativamente no turismo (Carrisso \& Pires, 2011). Destaca-se ainda que, "os fatores geológicos ligados à localização natural da jazida e ao grande volume das reservas, proporcionando longa vida útil aos empreendimentos, são fatores rígidos e imutáveis que impedem a mudança das áreas de extração" (Bacci et al., 2006).

A hipótese do estudo é de que a mineração interfere na saúde da comunidade e na questão da justiça ambiental, no que se trata de direitos dos indivíduos diante dos danos causados à população exposta a essa tensão ambiental, associada à vulnerabilidade da comunidade de São Thomé das Letras frente aos riscos impostos pela atividade extrativa local. Como a comunidade de São Thomé das Letras percebe os impactos da mineração da pedra são Thomé, atividade com intimidade histórica e física na comunidade, nos campos da saúde coletiva e justiça ambiental? Essa é a questão que se busca resolver, ou pelo menos entender, com esse trabalho. Nessas condições, este estudo teve o propósito de investigar a percepção dos moradores do município 
de São Thomé das Letras em relação às repercussões da mineração nos âmbitos da saúde coletiva e da justiça ambiental.

\subsection{O contexto: a mineração e a cidade de}

São Thomé das Letras

A cidade de São Thomé das Letras com aproximadamente 6.655 habitantes, está localizada na região sul do estado de Minas Gerais. A atividade de mineração é o setor econômico que mais emprega, com 1.027 postos de trabalho, de acordo com dados do Instituto Brasileiro de Geografia e estatística (IBGE, 2010). Conforme o Plano de Ação para a Sustentabilidade para o setor de Rochas Ornamentais - Quartzito em São Thomé das Letras: “A vocação econômica de São Thomé das Letras está centrada na extração da pedra São Tomé, atividade secular, exercida pela população local e vizinhanças, em empresas de estrutura principalmente familiar" (FEAM, 2009, p. 24).

Assim, esta pequena cidade tem na mineração do quartzito, sua "vocação econômica" e razão de viver, pois é a principal atividade econômica e a maior fonte de empregos formais. Tal "vocação", traduzida como viabilidade econômica para exploração, se revelou no início da década de 1950, ganhando maior vigor no início dos anos de 1970 (Fernandes et al., 2003).

Entretanto, a atividade extrativa em São Thomé das Letras tem suas peculiaridades, principalmente quando se volta para a história da mineração, entrelaçada com a formação da cidade. Ainda no século XVIII, os quartzitos já eram utilizados pela população local na construção civil, importante traço da cultura local (FEAM, 2009). Juntamente com a lenta formação da cidade, a mineração de quartzito expandiu-se, primeiro como matéria-prima da construção civil local e mais tarde, na década de 1940, com o início da exploração comercial da rocha por pequenas empresas. No ano de 2008, foi estimado que $25 \%$ da produção (100.000 t) se destinavam ao comércio exterior (FEAM, 2009).

O produto extraído na cidade, a "pedra São Thomé", é conhecido por seu alto nível de pureza, no tocante à concentração elevada de quartzo em sua formação, nível de pureza diretamente associado ao risco à saúde dos trabalhadores expostos no processo. Uma pesquisa realizada no ano de 2011 por Barbosa et al. (2011), em São Thomé das Letras, evidenciou o problema de saúde pública gerado pela exploração mineral na cidade. Em uma amostra de 185 trabalhadores, de um universo de 34 diferentes empresas, 46 deles foram diagnosticados com silicose, apontando uma prevalência de $24,9 \%$.

A mineração em São Thomé das Letras também tem outra particularidade relevante: sua proximidade geográfica com o centro urbano local. A lavra é vizinha à cidade, como pode ser observado na Figura 1. Os depósitos de mineração, por fatores geológicos imutáveis, estão localizados muito próximos à cidade, sendo possível em dias em que sopra um vento constante, perceber as finas partículas de sílica pairando e brilhando no ar. Neste cenário, além dos próprios trabalhadores envolvidos com a mineração, pela intimidade geográfica entre cidade e lavra, os moradores da cidade também estão expostos aos impactos da mineração, em especial à sílica livre cristalina pela dispersão dessas partículas no ar. 


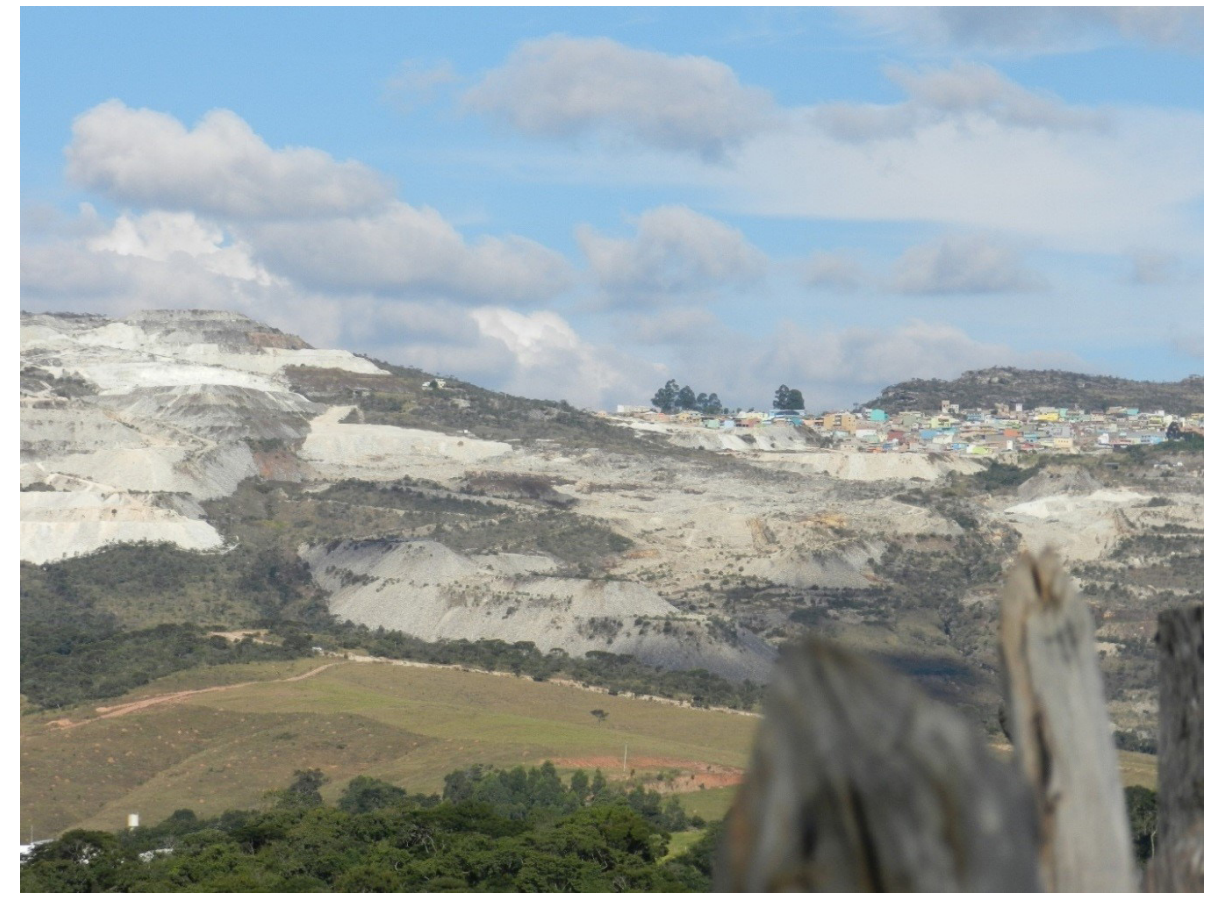

FIGURA 1 - Proximidade entre as lavras de mineração, destacando a paisagem degradada, e a cidade de São Thomé das Letras, ao fundo. FONTE: elaborada pelos autores, 2017.

\section{Percurso metodológico}

O trabalho utiliza pesquisa etnográfica para buscar compreender a percepção da população de São Thomé das Letras sobre os efeitos da mineração de quartzito no campo da saúde e da justiça ambiental, visto a ocorrência de silicose nos trabalhadores da atividade extrativa e a proximidade das frentes de lavra em relação ao centro urbano local.

A pesquisa também se caracterizou por ser interdisciplinar, buscando o diálogo entre os campos da saúde coletiva e ciências sociais, numa tentativa de compreender mais amplamente as relações en- tre a atividade extrativa local, a saúde pública e a justiça ambiental.

Para a coleta de dados, uma das autoras do estudo morou na comunidade entre março a julho de 2017, durante 102 dias. Durante este período, foram realizadas 25 entrevistas semiestruturadas, gravadas e não-gravadas, com os trabalhadores (três) e ex-trabalhadores da mineração (dez), bem como com outros membros da comunidade (doze). Contudo, essa não foi a única forma de coleta de dados, conversas informais e o diário de campo, foram importantes instrumentos para a compreensão do modo de vida da população em São Thomé das Letras. 
Para a concepção de uma pesquisa qualitativa não há, como na pesquisa quantitativa coleta de dados para comprovação de teoria ou de modelo preexistente, mas sim o envolvimento da pesquisadora diretamente com seu objeto, buscando compreensões. Assim, numa concepção etnográfica de observação participante, na qual a pesquisadora mergulha profundamente em campo, é impossível que este não seja contaminado por aquele e que a própria pesquisa não contenha traços de subjetividade.

A investigação junto aos membros da comunidade sobre se encontrarem em uma situação de injustiça ambiental não era viável, pois não se podia partir do pressuposto que todos sabiam o significado do termo, restrito ainda ao contexto acadêmico. $\mathrm{O}$ procedimento escolhido foi perguntar às pessoas, residentes próximas das frentes de lavra, se elas achavam que a mineração afetava a comunidade e ouvir atentamente o relatado ${ }^{1}$.

\section{Caminhos de pedra: memória, saúde e justiça ambiental.}

A mineração de quartzitos faz parte da vida de São Thomé das Letras, a pedra se faz presente nas paredes das casas, na pavimentação das ruas, no artesanato produzido na comunidade, compõe a cultura local. Pensar a cidade sem aquela que é sua principal atividade econômica, ainda que aos poucos venha perdendo espaço para o turismo crescente e cada vez mais organizado, é, no momento, inviável. Uma relação íntima e histórica como essa deixa marcas naqueles que constituem o corpo social do município, em seus sujeitos.

As falas dos entrevistados, as observações realizadas pela pesquisadora e as conversas informais, desenroladas no dia a dia, sem compromisso, mas nem por isso despidas de conteúdo, foram analisadas na tentativa de compreender a percepção da comunidade em relação aos impactos da mineração nos âmbitos da saúde coletiva e da justiça ambiental.

\subsection{Pedreiras e memória}

A extração mineral local e a própria cidade de São Thomé das Letras têm histórias que caminham lado a lado, se confundindo em alguns momentos e apartando-se em outros. Essa confluência ganha vida no discurso daqueles que vivem a mineração em seu cotidiano, para os são-tomeenses. As pedreiras não são apenas fonte de renda da cidade, mas também parte do que ela é, de sua paisagem, repleta das grandes pilhas de rejeitos ou enormes frentes de lavras abandonadas, baldias, que vêm sendo gradativamente transformadas, ocupadas pela população.

Lembranças como a do extrator de pedra, que teve seu primeiro contato com o pai, também extrator, e ainda menino, o ajudou a construir aquela que seria a casa da família, toda de pedra São Tomé, das paredes ao teto. Bem viva a memória de como nos dias de chuva, as paredes, erigidas sem massa, sem cimento, apenas com pedras encaixadas, permitia

\footnotetext{
${ }^{1}$ A presente pesquisa foi submetida à Plataforma Brasil e analisada por comitê de ética, especificamente pelo Comitê de Ética e Pesquisa da Universidade Vale do Rio Verde (UNINCOR/MG), sob o Certificado de Apresentação para Apreciação Ética (CAAE) n 65994017.0 .0000 .5158 para que estes preceitos fossem preservados. O parecer consubstanciado deste comitê, sob o número 2.041.330, aprovou sua realização.
} 
a infiltração de água e molhar todo o interior da residência, e do telhado, de pesadas lascas de pedra sobre madeira, projeto que hoje ele acha inseguro.

As memórias da comerciante, que quando menina brincava nas pedreiras, e chegava em casa sempre cheia de cortes e machucados ou de quando ia com a mãe até as áreas de extração catar os rejeitos chamados "cavacos", pedaços menores da pedra usados em casa e no artesanato local. Seus irmãos, nesse tempo, já acompanhavam o pai para aprenderem o ofício de extrator.

Essas memórias, apesar de singelas, demonstram como a pedra São Tomé faz parte do dia a dia daquela população e de sua cultura e de seus saberes tradicionais. Importante esse entendimento para que se possa compreender o processo de insensibilização dessa população frente à degradação ocasionada pela atividade econômica predatória desenvolvida em seu território (Acserald et al., 2009). Existe uma profunda identificação entre a população e a atividade extrativa, seja pela ideia de "vocação" do território, ou mesmo pelo grau de dependência econômica desta população em relação ao processo de mineração. Essa dependência é uma forte aliada na formação das vulnerabilidades dessa comunidade.

\subsection{A atividade extrativa}

Muito foi dito, durante as entrevistas e conversas, sobre a atividade mineradora em si, sobre empresas, suas instalações, o destino dos empreendimentos fechados, recolhimento de impostos, as perturbações ambientais causadas e até mesmo sobre o ofício de extrator, como era realizado antes e como se transformou com a inserção de novas tecnologias, como os explosivos.
A tecnologia é, incontestavelmente, um grande transformador do modo de extração local, historicamente manual e rústica, como informado por um dos extratores entrevistados quando descreveu que "Tem que furar umas mininha com broca e explodia e depois cortava, nóis tirava no seco mesmo" (Entrevistado nº 01, São Thomé das Letras, 2017), ou ainda quando menciona que "Sujeira não tinha máquina pra tirar nóis tirava tudo no carrinho" (Entrevistado $n^{\circ} 01$, São Thomé das Letras, 2017). Sobre a extração antes dos explosivos alguns entrevistados chegaram a descrever o processo:

Nóis sentava até em cima do martelete assim pra furar a mina. [...] . Nóis fala banco, você limpa assim [explica com gestos], ai ia um na frente com uma broca pequena, outro com a outra broca mais maior e outro com a broca de três metro. Ai nóis sentava até no martelo ... (Entrevistado ${ }^{\circ} 1$, São Thomé das Letras, 2017. Informação verbal).

Ai vai desmanchando um pedaço, a hora que acaba aquele o cara volta de novo e vai tirando assim, entendeu? Depois que explode tira aquilo e vai separando, tira o lixo fora, joga, põe lá no lugar mais longe, afastado, e o que é comercial o cara leva pra outra cidade e depois começa de novo, no mesmo paredão, e vai tirando de novo (Entrevistado $\mathrm{n}^{\circ} 10$, São Thomé das Letras, 2017. Informação verbal).

$\dot{E}$, tem que começar, por exemplo, a gente pega um lugar alto e começa lá em cima e vai até o final, depois tem que começar de novo, então faz tudo, tirar o que não presta, o que presta, jogar fora e mandar pra fora, pra outra cidade, para exportação, entendeu? Tem o que serve e o que não serve, né? (Entrevistado $\mathrm{n}^{\circ} 10$, São Thomé das Letras, 2017. Informação verbal). 
As empresas são as responsáveis pela transformação tecnológica na extração e uma delas marcou os extratores locais. Há alguns anos se instalou uma empresa multinacional na cidade, que segundo os relatos, trouxe maquinário pesado capaz de aumentar a capacidade de extração. Devido a isso, alguns dos entrevistados, relacionam a acelerada devastação ambiental em São Thomé a essa empresa em específico, em relatos como "levou o dinheiro e deixou os buracos" (Entrevistado no 03, São Thomé das Letras, 2017). Em relato não-gravado o entrevistado de número 09, ex-funcionário da empresa contou que apesar de a empresa destruir o meio ambiente da cidade os extratores gostavam de trabalhar lá, pois a empresa era a que pagava melhor na época.

Em relação ao meio ambiente, não só a modificação da paisagem pelas montanhas de rejeito é notada em São Thomé das Letras. As perturbações ao meio ambiente causadas pela mineração vão ainda além. Fazem parte da rotina são-tomeense o convívio com as explosões, os estampidos e tremores, os caminhões pesados transitando a todo o momento e o barulho das máquinas trabalhando, esculpindo grosseiramente as montanhas.

A cidade, que tem como outra importante fonte de trabalho e renda o turismo, tem grande parte de seus atrativos naturais marcados pela indústria local, como os córregos que abastecem algumas cachoeiras, bastante assoreados pelos rejeitos. Possivelmente este seja o conflito mais nítido na realidade da região, diante do desafio relevante de conciliar a mineração com o turismo. A mineração é, no modelo estabelecido, considerada como um risco importante para o ecoturismo como uma alternativa econômica, podendo comprometê-lo (Olivieri \& Araujo, 2011; Fleischer, 2006).

\subsection{A saúde e a mineração}

Impossível trabalhar com a atividade na cidade, nas atuais circunstâncias, e não ter contato com o pó originado da quebra da rocha. Sobre esse convívio cotidiano com a poeira, alguns dos relatos da vivência:

Entrei em contato direto com aquilo lá, você tirando a pedra lá e a poeira tá subindo né? (E4, São Thomé das Letras, 2017).

Direto, principalmente na parte de extração, que você já está direto né, ai mexe até com explosivo, quando o pessoal explode vem muito cheiro de pólvora, essas coisas normais mesmo que acontecem em pedreira, sabe? Aí quando você está nessa parte de extração você está lidando com tudo ali, sabe? É normal mesmo, lá na pedreira (E11, São Thomé das Letras, 2017. Informação verbal).

Acaba entrando, só por isso que a gente tem que evitar né, hoje tem caminhão pipa, a gente joga água pra não ter o pó mesmo, sabe? (E2, São Thomé das Letras, 2017. Informação verbal).

O uso de equipamentos de proteção individual, medida de caráter paliativo, pode reduzir, com importantes limitações, o risco de exposição, contudo, pelos relatos é perceptível que nem sempre as empresas os disponibilizam, além de haver resistência dos próprios extratores quanto ao seu uso.

Usava. Não nóis usava agora de pouco. Em 68/70 não tinha. Trabalhei em uma firma boa mas não tinha não (E1, São Thomé das Letras, 2017. Informação verbal). 
Não, não, nessa época não tinha não. Isso foi de uns vinte e cinco anos pra cá. Que aí já começou, o pessoal já começou essas doenças, a silicose que eles fala, areia no pulmão. Aí o pessoal já começou a cuidar né. Agora trabalha com máscara, tudo certinho (E2, São Thomé das Letras, 2017. Informação verbal).

Naquela época não usava nada, nada, trabalhava de chinelo, de bermuda, era assim, mais no começo era de qualquer jeito, mais pro fim no ultimo tempo que eu trabalhei ai usava, tinha botina, luva, máscara, usava EPI, só que o pessoal mesmo tendo EPI a maioria não usava, capacete, trabalhou muito tempo sem esse equipamento, agora no fim demora a acostumar né, muita gente não adapta. Até hoje em dia mesmo se você for nas mineradoras você pode ver que muitos não tá usando, não usa botina, luva, não usa capacete, abafador de som. Uns sim, usa, mas a minoria não usa não (E3, São Thomé das Letras, 2017. Informação verbal).

Tinha, usava as máscaras, mas é pouca máscara por semana, que dava, usava igual tempo de sol muito quente você usava a máscara poucas horas e tinha que jogar fora, como é que você ia trabalhar com aquilo o dia inteiro na cara, no rosto, suando tudo né, não tinha como (E4, São Thomé das Letras, 2017. Informação verbal).

A atividade, apesar de seus perigos, como já afirmado, é importante para a economia local e a sobrevivência do povo são-tomeense, corroborando com a questão das insensibilidades, e ainda contribui para que situações de injustiça ambiental não se tornem conflitos (Acserald et al., 2009).

Eu acho que é um risco que todo mundo corre, eu acho que é um risco que todo mundo corre porque o pó é muito fino né, acaba dando o vento e acaba trazendo pra cidade, é tudo pertinho, mas não porque causa mal que a gente quer que acabe também né, porque a gente vive disso, vai fazer o que? (E5, São Thomé das Letras, 2017. Informação verbal).

E quando não tiver mais pedra, menina, o que que o povo vai fazer? (Maria*. São Thomé das Letras. 2017. Informação verbal).

Sobre a silicose muito foi dito. Todos têm algum conhecido que apresenta o diagnóstico da doença, ou até mesmo faleceu em decorrência dela. As empresas fazem exames periódicos nos funcionários, mas existe a denúncia de que eles, os funcionários, nem sempre recebem o resultado, a não ser uma indicativa da empresa dizendo que está tudo certo nos exames de raios-x aos quais são submetidos. Abaixo alguns trechos das entrevistas:

Aqui em São Thomé? Tem vários casos, muito, muito. Inclusive um primo meu morreu dessa doença. Não tem (tratamento) e segundo o médico falou que quem pegou essa doença ai é um caminho sem retorno (E2, São Thomé das Letras, 2017).

Não, é, de seis em seis mês nós faz os exame, então tem aqui em são Thomé, outros já preferem em três corações, com uma clínica mais sofisticada. Né, e eu graças ao bom Deus, eu até hoje não deu problema não. Esses ano tudo, tiro chapa de pulmão, tem 35 (anos) o pulmão tá limpo (E2, São Thomé das Letras, 2017. Informação verbal).

Nas ultimas sim, nos últimos tempos que eu trabalhei fazia, mas não entregava pra gente, fazia e você 
nem sabia, por causa que as vezes tinha pessoa que tava doente e não sabia, não fala, todo mundo fazia, omitia os resultados, e tem muitos casos de silicose né, o pessoal é, pegou a silicose e muita gente que fazia exame e não sabia que tava de silicose, mesmo tendo feito os exames (E3, São Thomé das Letras, 2017. Informação verbal).

Ah eu conheço alguns, uns três ou quatro, mas já tão encostado fazendo tratamento, mas muita gente deve ter sim, sabe, que não fez exame, muitos não fizeram, sabe, outros que fizeram mais não teve o resultado, eu falo porque eu fiz várias vezes e nunca tive o resultado, não tava doente, sempre tava bom (E3, São Thomé das Letras, 2017. Informação verbal).

Apenas um dos entrevistados tem o diagnóstico de silicose. Em suas palavras:

Trabalho com turismo, hoje trabalho com turismo porque não tem condições mais de trabalhar na pedreira entendeu, porque o problema de silicose aí tive que ficar no turismo porque não tem condições [...]. Ah, é desde 2015 né que descobriu mesmo que tinha problema de silicose. Ai tive, tive que procurar um médico e o médico falou que se continuar na pedreira infelizmente vai chegar uma hora que você não guenta né, teve que parar (E4, São Thomé das Letras, 2017. Informação verbal).

A pedreira é sempre perigosa né, tem lá o pó da silicose, que, que mata as pessoas né, igual nosso amigo aqui, tem a silicose [aponta para o quarto entrevistado, que estava conosco], não pode mais trabalhar em pedreira. Então hoje a pessoa que trabalha em pedreira tem muito disso, tem seus beneficios e tem o, tem a saúde que você joga fora (E6, São Thomé das Letras, 2017. Informação verbal). tem muitas pessoas na cidade, conhecidas, inclusive alguns até já morreram com problema com a pedra. Entendeu? Tipo silicose, mais uns problemas de saúde bem graves, que não aparece no dia, mas vem com o tempo. Entendeu? (E10, São Thomé das Letras, 2017. Informação Verbal).

A silicose é a doença mais temida na cidade, mas não é o único agravo que decorre da atividade de extração. Por ser uma atividade que exige muito esforço físico muitos dos trabalhadores sofrem com problemas musculares, na coluna, dores de cabeça, problemas de pele e de visão. Discorrem também sobre acidentes sofridos no trabalho, muitas vezes incapacitantes.

Só que eu tô encostado com um problema na perna, na musculação [...] a gente ficava muito tempo em pé, pega peso sabe, carrega caminhão, tirava aquelas laje, uma laje grossa assim [mostra com a mão, algo próximo dos 20/30 cm] e jogava aquilo no caminhão então era muito peso aí que eu machuco (E1, São Thomé das Letras, 2017. Informação Verbal).

Olha na pedreira sim, porque eu tenho a coluna, a maioria das pessoas tem problema na coluna, a coluna é meio envergada, torta, dá uma envergadu$r a$, trabalha muito abaixado e com muito peso e, e postura não própria né, muito forçando a coluna (E3, São Thomé das Letras, 2017. Informação Verbal).

Eu acho que sim. Eu acho que sim. Principalmente em questão de micose, quando eu trabalhava na pedreira eu tinh a muita micose, no braço, no pescoço por conta da areia. Depois que eu parei de trabalhar com pedra, com pó de pedra a micose sumiu (E9, São Thomé das Letras, 2017. Informação Verbal). 
Muito. Várias, várias lesões, sabe, várias lesões, na mão, como nos pés, na vista também, o sol também, que pega direto também, sem proteção nenhuma, e a coluna também, que agrava muitíssimo a coluna, trabalha muito agachado, entendeu? Fica muito no vai e vem, então atrapalha bastante (E10, São Thomé das Letras, 2017. Informação Verbal).

Mais grave que eu saiba é mais a silicose mesmo e alguns acidentes que tem, o cara cai, machuca. Teve um cara há muitos anos trás, não tive muito contato com ele, mas eu sei da história de um senhor que perdeu o braço com explosão, tem vários relatos assim, pequenos. Muito grandes de mutilar mesmo, muito grande não tem não, mas pequenos tem vários, de cortar a mão, de cortar a perna, cortar dedo, entendeu? Porque é pedra, pedra é isso, você mexe com aço, você tira com o ferro, então você utiliza ali e sempre tá machucando. Gravemente pouquíssimos, mas alguns machucam grave, entendeu. Ai tem desmoronamento de sujeira, de pedra, então sempre tem alguns acidentes (E10, São Thomé das Letras, 2017. Informação verbal).

Importante recorrer ao modelo etnoepidemiológico de Almeida Filho (2004) da teoria do modo de vida e saúde, para determinação social de doenças crônicas e não-transmissíveis. Nesse modelo, em que se entrelaçam valores como a reprodução, o consumo, o modo de vida e a produção, a configuração do risco é construída por fatores como classe social, processo laboral e práticas sociais. Aqui, encarar o processo de trabalho como determinante de situações de risco é essencial e assim deve ser feito quando se debruça sobre a realidade da cidade de São Thomé das Letras. A mineração faz parte o modo de vida do são-tomeense, a pedra está presente nas práticas cotidianas dessa população, e é fator fundamental na composição das vulnerabilidades dessa população.

O processo saúde-doença é mais que apenas biológico, abrangendo também circunstâncias sociais e culturais (Minayo, 2010; Porto, 2012). Em São Thomé das Letras é fundamental também pensar a dimensão ambiental da saúde (Porto et al., 2004) e discutir acerca dos riscos enfrentados por alguns grupos, como os trabalhadores da atividade extrativa, mais expostos a agentes nocivos e ao meio ambiente desequilibrado que outros.

Frente a esses relatos é, então, possível compreender um pouco dos reflexos da mineração na saúde do povo são-tomeense, principalmente na daqueles que trabalham diretamente na mineração. Acidentes, doenças crônicas, problemas na coluna, na visão são algumas das preocupações que afligem esses trabalhadores e moradores da cidade. Será que aceitar passivamente esses reveses por dependerem economicamente da atividade é a única saída para esse povo que deixa seu suor e saúde nas pedreiras?

\subsection{Justiça ambiental}

As frentes de lavra do quartzito em São Thomé das Letras são vizinhas à zona urbana da cidade, e afligem os moradores quanto aos possíveis riscos que trazem à sua saúde. Mas será que só a saúde é afetada pela mineração? As lutas por justiça ambiental buscam encontrar meio ambiente equilibrado e equânime para as populações, e que essas não tenham de suportar desigualmente adversidades causadas pelos empreendimentos econômicos (Acserald, 2009). A proximidade das pedreiras ao centro urbano ocorre tanto por uma questão histórica da formação da cidade (FEAM, 2009), quanto 
por razões geológicas da localização das jazidas e de sua imutabilidade (Rammê, 2012).

Ah a mais perto é essa que tem aqui em cima né, acho que São Tomé inteiro vive perto, a cidade é o miolo né, a extração fica em volta né? (E5, São Thomé das Letras, 2017. Informação verbal).

E eu acho que para nós que não trabalha e mora já, que nem nós estamos dentro da pedreira, pros dois lados, você vê do lado de baixo, do lado de cima, eu acho que é até perigoso pra nós, vai ver que, se tiver nós nem sabe, que tem essa doença (E7, São Thomé das Letras, 2017. Informação verbal).

As frentes de lavra como vizinhas das casas da cidade causam impactos e preocupações para os são-tomeenses, a despeito de que pelos relatos, seja possível perceber uma diminuição nas explosões mais próximas da cidade com o tempo.

No começo sim, porque o pessoal usava explosivo e quando dinamitava aquela área aquele pó vinha tudo pra cidade, hoje foi embargado nas beiras da cidade não funciona mais, não trabalha mais, e aguando, vão jogando água, se tiver uma máquina, que é uma retroescavadeira, ai o caminhão tá sempre ali aguando pra evitar mesmo o pó pra não ter mais problema (E2, São Thomé das Letras, 2017. Informação verbal).

Hoje em dia acho que não, porque um tempo pra trás era muito explosões, ainda tem, mas hoje em dia é mais controlado, de um tempo pra traz era descontrolado e tinha explosões muito fortes, que acaba afetando a estrutura das casas (E3, São Thomé das Letras, 2017.Informação verbal).
Mas assim com a pedreira o pó né, que o pó mesmo você não trabalhando tem muita poeira na área das pedreiras, essas coisas as vezes você vê no ar brilhando coisinha brilhando é a mica né, da pedra, sei lá o que que é, é a areia que é super fina que você respira e ai dá silicose, é dessa areia, mas a silicose te falando o pessoal que contrai mais é pessoal que tá trabalha em máquina, compressor, na serra, perfuratriz, que o pó é mais intenso, na perfuração, que faz os buracos pra explodir, na serra também, quando tá nos depósitos, industrializando pedra, ai o pó é mais fino, quando tá serrando o pó é super mais fino do que o da pedreira (E3, São Thomé das Letras, 2017. Informação verbal).

\section{Outra preocupação são os ventos, que} sopram o pó fino da sílica e a cobrem como névoa a cidade.

Eu acho que é um risco que todo mundo corre, eu acho que é um risco que todo mundo corre porque o pó é muito fino né, acaba dando o vento e acaba trazendo pra cidade, é tudo pertinho, mas não porque causa mal que a gente quer que acabe também né, porque a gente vive disso, vai fazer o quê? (E5, São Thomé das Letras, 2017. Informação verbal).

Traz, traz sim [o pó] porque quando trabalha nas pedreiras lá, que dá explosão e começa a ventar esse pó vem pra cidade também, aqui já tem um pouco, mas lá, quando explode lá, aquele pó levanta tudo pra cima, e vem pra cá também uai (E4, São Thomé das Letras, 2017. Informação verbal).

Olha, eu acho que os dejetos que ficou da pedreira que traz pó né, você vê que, você mesmo está morando aqui você vê, você limpa a janela quando vê você olha já está, no outro dia já tem aquela areinha. Mas acho que não tem como evitar isso menina, só se replantar, 
reflorestar, um pouco onde não tira mais nada, onde não tira mais nada da pedra, aí ficou só sujeira né, e o pó da pedra que para muitos já fizeram mal (E7, São Thomé das Letras, 2017. Informação verbal).

Os danos ao meio ambiente fazem parte do cenário gerador das vulnerabilidades sociais, uma vez que, segundo Henriques \& Porto (2015), prejudicam a sobrevivência das comunidades e causam agravos a saúde coletiva da população. Não é difícil, estando em São Thomé das Letras, perceber os danos ao meio ambiente causados pela mineração, e como esses compõem o quadro de vulnerabilidade, ou para Porto (2012), obstáculos à promoção de ciclos de vida dignos.

O movimento por justiça ambiental denuncia a distribuição desigual dos riscos sobre populações vulneráveis (Rammê, 2012). Na realidade vivida em São Tomé, devido às tímidas dimensões da cidade, os riscos provenientes da atividade minerária que se expressa por explosões, tremores e a dispersão da sílica, repercutem praticamente sobre toda a cidade.

Retornando à "vocação" da cidade para a mineração, segundo o jargão empregado pelo capital, a injustiça ambiental presente foi construída historicamente, cidade e mineração, distinta do modo tradicional de transferir atividades de risco para a proximidade de regiões vulneráveis. O capital ou os mecanismos de mercado, mesmo que expresso em pequenas empresas, encontraram um território a ser explorado, provocando degradação e desigualdade ambiental, junto a uma população dócil e refém do processo, as denominadas "classes ambientais" com possibilidade reduzida de se afastar da atividade minerária (Acserald, 2002). Não foram identificados movimentos ou algum gesto que acenasse para esta direção de justiça ambiental para combater esta assimetria social, assinaladas pelas desigualdades observadas. Acredita-se que a convivência histórica com a mineração seja e esteja tão arraigada entre a população, que qualquer manifestação pode ser traduzida como uma "traição aos interesses da cidade" ou uma tendência a gerar desemprego na cidade (Acserald, 2002). Talvez a razão do silêncio e da omissão dos que sofrem ou percebem os danos seja esta.

\subsection{Mineração e trabalho}

Não é razoável abordar saúde e justiça ambiental em São Thomé das Letras sem incorrer no mundo do trabalho do lugar e saber como foram e são construídas as relações na atividade mineradora na cidade. Em muitos dos discursos falas sobre questões do trabalho, nem sempre diretamente relacionadas às categorias acima descritas, mas de modo a se entrelaçar a elas, se destacam elementos que se mostram profícuos no esforço de compreender um pouco da dinâmica daquela comunidade.

O trabalho infantil também já foi uma realidade na cidade. Os meninos iam, desde muito novos, acompanhar os pais nas pedreiras, para aprender o ofício, conforme os relatos a seguir:

Uma vez eu morava na roça eu trabalhava na chapa$d a$, vinha a pé. Nessa época não tinha nem doze anos não, ai eu não guentava carrega um carrinho. Tinha um rapaz aqui embaixo aqui que dava empreita pra nóis, nóis morava na roça aí ele dava empreita e nóis acabava de tirar, carrinho de roda de ferro, tinha de ladriar igual isso daqui [e mostra o chão da praça, de pedras colocadas uma ao lado da outra, formando uma superficie plana] senão não andava. Ai eu meava só o carrinho, puxa as pedras eu não aguentava (E01, São Thomé das Letras, 2017. Informação verbal). 
É, que nem eu tô te falando, meu pai começou a trabalhar com oito anos ué. E meu irmão não mexe com extração de pedra, mas ele faz casa de pedra, casa, muro, essas coisas, ele e meu filho (E05, São Thomé das Letras, 2017. Informação verbal).

Então, eu comecei era menor de idade ainda, aqui em São Thomé não tinha nada, a única coisa que começou na época foi a pedreira, entendeu? Então era a única opção, entendeu? Era só trabalhar, trabalhar na pedreira. Não tinha escola na época, não tinha nada (E10, São Thomé das Letras, 2017. Informação verbal).

Há também o problema da informalidade no cenário local. Há relatos de empresas que funcionam na clandestinidade, além de outras que nem mesmo assinam as carteiras de seus profissionais.

É, depois eu parei um pouco, trabalhei picado, sem carteira, trabalhei muito tempo sem carteira. Mas que eu tenho de pedreira já tem mais de quarenta anos (E01, São Thomé das Letras, 2017. Informação verbal).

A informalidade no setor não atinge apenas a contratação de profissionais sem carteira assinada, mas conforme relatado pelo nono entrevistado, existem pedreiras ilegais em atividade na cidade. É comum que os extratores prefiram trabalhar na ilegalidade, uma vez que essas empresas pagam mais do que as empresas formais.

Aqui novamente se faz importante relembrar que a justiça ambiental deve estar também no ambiente de trabalho, onde o trabalhador não deve ter de escolher entre seu emprego e o risco (Acserald et al., 2009) e o trabalho informal que, sem amparo legal ao trabalhador, já é um risco, além de todos os outros que um extrator de pedra já está sujeito no dia a dia de sua atividade laboral.

A extração de pedras é um trabalho árduo, que impõe grande esforço físico e que deixa profundas marcas em seus trabalhadores, tanto em seus corpos como em suas memórias. Há profunda ligação entre extrator e extração, não apenas por ser nas pedreiras que muitos dos homens tiram o sustento de suas famílias, mas também por terem aprendido a profissão com seus pais, e por considerar a profissão algo de família.

\section{Considerações finais}

Esta pesquisa teve o objetivo de investigar a percepção de moradores da cidade de São Thomé das Letras sobre questões de justiça ambiental e saúde coletiva, tendo como elemento balizador a importante atividade mineral no local. Verifica-se que a "vocação econômica" da cidade, ditada e construída pelo modelo de desenvolvimento predominante, impõe essa vocação da mineração na vida e na memória das pessoas do lugar. Essa vocação, pela pedra e sua extração, tem jazidas profundas no histórico e na geologia da região. A cidade orbitada pelas lavras parece ser prisioneira desse processo de mineração, que tem escrito e moldado a história dela. As falas de moradores revelam, de certo modo, que são reféns da atividade, a despeito dos riscos que ela representa no cenário da saúde coletiva e da justiça ambiental. A mesma mineração que oferece a sobrevivência ou a subsistência de moradores, direta ou indiretamente, é aquela que degrada a paisagem e pode degradar a saúde, pelo risco de silicose. O impacto de processos de mineração em São Thomé das Letras, tema recorrente e predominante na realidade 
do estado de Minas Gerais, deve ser repensado à luz de uma proposta de desenvolvimento equânime e sustentável, que ofereça digna qualidade de vida a todos os moradores.

\section{Referências}

Acserald, H. Justiça ambiental e construção social do risco. Desenvolvimento e Meio Ambiente, 5, 49-60, 2002. Disponível em: https://revistas.ufpr.br/made/article/ view/22116/14480

Acselrad, H.; Mello, C. C. do A.; Bezerra, G. das N. O Que é Justiça Ambiental. Rio de Janeiro: Garamond, 2009.

Almeida-Filho, N. de. Modelos de determinação social das doenças crônicas não-transmissíveis. Ciência \& Saúde Coletiva, 9(4), 865-884, 2004. Disponível em: https://www. scielo.br/pdf/csc/v9n4/a09v9n4.pdf

Bacci, D. de La C.; Landim, P. M. B.; Eston, S. M. de. Aspectos e impactos ambientais de pedreira em área urbana. Rem: Revista da Escola de Minas de Ouro Preto, 59(1), 47-54, 2006. Disponível em: https://www.scielo.br/pdf/ rem/v59n1/a007.pdf

Barbosa, M. S. de A.; Carneiro, A. P. S.; Maciel, J. G. F. S.; Moronte, E. A.; La Rocca, P. de F.; Santos, A. R. M. Silicose em trabalhadores de quartzito da região de São Thomé das Letras - Minas Gerais: dados iniciais indicam um grave problema de saúde pública. Revista Brasileira de Saúde Ocupacional, 36(123), 177-184, 2011. Disponível em: https://www.scielo.br/pdf/rbso/v36n123/a18v36n123.pdf

Carrisso, R. C. C.; Pires, D. C. B. A Pedra "São Thomé": tensões e conflitos entre a APL mineral e o turismo. In: Fernandes, F. R. C.; Enriquez, M. A.; Alamino, R. de C. J. (Eds.). Recursos Minerais e Sustentabilidade Territorial. Arranjos Produtivos Locais. v. 2. Rio de Janeiro: CETEM/ MCTI, p.115-138, 2011. Disponível em: <http://mineralis. cetem.gov.br/bitstream/cetem/467/1/Vol_2_APL_TOTAL. pdf $>$ Acesso em: ago. 2020.

DNPM - Departamento Nacional de Produção Mineral. Sumário Mineral 2014: Rochas Ornamentais e de Reves- timento, 2014. Disponível em: < https://www.gov.br/anm/ pt-br/centrais-de-conteudo/dnpm/sumarios/rochas-ornamentais-de-revestimento-sumario-mineral-2014/view $\geq$. Acesso em: ago. 2020.

DNPM - Departamento Nacional de Produção Mineral. Sumário Mineral 2015: Rochas Ornamentais e de Revestimento, 2015. p. 100-101. Disponível em: < https://www. gov.br/anm/pt-br/centrais-de-conteudo/dnpm/sumarios/ sumario-mineral-2015/view>. Acesso em: ago. 2020.

FEAM - Fundação Estadual do Meio Ambiente/Minas Gerais. Plano de ação para a sustentabilidade do setor de rochas ornamentais - quartzito São Thomé das Letras, 2009. Disponível em: <http://www.FEAM.br/images/ stories/arquivos/producaosustentavel/plano_de_acao_rochas_ornamentais_quartzitos.pdf $>$. Acesso em: ago. 2020.

Fernandes, T. M. G.; Godoy, A. M.; Fernandes, N. H. Aspectos geológicos e tecnológicos dos quartzitos do centro produtor de São Thomé das Letras (MG). Revista Geociências, 22, 2, 129-141, 2003. Disponível em: https://www. revistageociencias.com.br/geociencias-arquivos/22_2/3.pdf

Fleischer, D. I. R. São Tomé das Letras e Lagoa Santa: mineração, turismo e risco ao patrimônio histórico e natural. Cadernos de Campo, 14/15, 21-39, 2006. Disponível em: http://www.revistas.usp.br/cadernosdecampo/article/ view/50096/54216

Henriques, A. B.; Porto, M. F. de S. Mineração, agricultura familiar e saúde coletiva: um estudo de caso na região de Itamarati de Minas-MG. Physis Revista de Saúde Coletiva, 25(4), 1361-1382, 2015. Disponível em: https://www.scielo.br/pdf/physis/v25n4/0103-7331-physis-25-04-01361.pdf

IBGE - Instituto Brasileiro de Geografia e Estatística. Cidades: São Thomé das Letras, 2010. Disponível em: $<$ http:// cidades.ibge.gov.br/xtras/perfil.php? codmun $=316520>$. Acesso em: out. 2017.

Minayo, M. C. de S.. O Desafio do Conhecimento: Pesquisa qualitativa em saúde. São Paulo: Hucitec, 2010.

Olivieri, R.; Araujo, E. Exploração de quartzito em São Thomé das Letras (MG) passa por reestruturação. In: Fernandes, F. R. C.; Alamino, R. de C. J.; Araujo, E. R. (Eds.). Recursos Minerais e comunidade: impactos humanos, socioambientais e econômicos. Rio de Janeiro: CETEM/ 
MCTI, p. 286-289, 2014. Disponível em: <http://mineralis. cetem.gov.br/bitstream/cetem/1729/1/Livro_Recursos_Minerais_E_Comunidade_FormatoA4_em14_outubro_2014. pdf>. Acesso em: ago. 2020.

Porto, M. F. de S. Uma Ecologia Política dos Riscos: princípios para integrarmos o local e o global na promoção da saúde e da justiça ambiental. Rio de Janeiro: Editora Fiocruz, 2012.

Porto, M. F. de S.; Pivetta, F.; Soares, M.; Moreira, J.; Freitas, C. M. de. Abordagens Ecossociais: pensando a complexidade na estruturação de problemas em saúde e ambiente. In: Anais do 20 Encontro da ANPPAS. São Paulo, 26-29 de mai. 2004. Disponível em: < http://www.anppas. org.br/encontro_anual/encontro2/GT/GT12/marcelo_firpo. pdf >. Acesso: ago. 2020.
Rammê, R. S. Da justiça ambiental aos direitos e deveres ecológicos: conjecturas políticos-filosóficas para uma nova ordem jurídico-ecológica. Caxias do Sul, RS: Educs, 2012.

Ribeiro, F. S. N. (Coord.). Brasil. O mapa da exposição à sílica no Brasil. Rio de Janeiro: UERJ; Ministério da Saúde, 2010. Disponível em: <http://bvsms.saude.gov.br/bvs/ publicacoes/mapa_exposicao_silica_brasil.pdf $>$. Acesso em: jul. 2018. 